\title{
Modular Multi-Level DC-DC Converter for High-Power and High-Voltage Applications
}

\author{
Ricardo Vidal-Albalate*, Diego Soto-Sanchez ${ }^{\dagger}$, Enrique Belenguer*, Rubén Peña ${ }^{\ddagger}$ and Ramon Blasco-Gimenez ${ }^{\S}$ \\ *Universitat Jaume I de Castelló, Castelló de la Plana, Spain - Email: rvidal@uji.es, efbeleng@uji.es \\ $\dagger$ Universidad de Magallanes, Punta Arenas, Chile - Email: diego.soto@umag.cl \\ ‡Universidad de Concepción, Concepción, Chile - Email: rupena@udec.cl \\ §Universitat Politecnica de Valencia, Valencia, Spain - Email: r.blasco@ieee.org
}

\begin{abstract}
A transformer-less DC-DC Modular Multi-level Converter (DC-DC-MMC) topology based on H-bridge cells is proposed in this paper. The suggested DC-DC-MMC can be used to either control the power flow in a HVdc grid or interconnect HVdc lines with different voltage levels. Branch energy and current control loops are presented as well as a cell capacitor voltage balancing strategy. Finally, the operation of the converter is validated by means of PSCAD simulations. Results for the operation of the DC-DC-MMC controlling the power flow between two HVdc grids with different voltage levels are presented.
\end{abstract}

Keywords-DC-DC converter, HVdc grids, Modular multi-level converter, Power flow control.

\section{NOMENCLATURE}

Upper and lower branches of the converter are denoted with subscripts " 1 " and " 2 ", respectively. Subscript $x$ can take the following values: $i s h$ (input shunt branch), ise (input series branch), de (derivation branch), ose (output series branch) and osh (output shunt branch).
$I S h B_{1,2} \quad$ Input Shunt Branch.
$I S e B_{1,2} \quad$ Input Series Branch.
De $B_{1,2} \quad$ Derivation Branch.
$O S e B_{1,2} \quad$ Output Series Branch.
$O S h B_{1,2} \quad$ Output Shunt Branch.
$i_{x 1,2} \quad$ Branch current.
$I_{x 1,2}$
$i_{i u 1,2}$
$i_{\text {ou } 1,2}$
$i_{q}$
$V_{m}$
$v_{u}$
$I_{i u 1,2}$
$I_{\text {ou } 1,2}$
$V_{u}$
$I_{q}$
$\pm V_{i}$
$\pm V_{o}$
$I_{d c i}$
$I_{d c o}$
$V_{c}^{*}$
$V_{c j}$
C
$W_{x 1,2}$
$\bar{W}_{x 1,2}$
DC component of the branch current $i_{x 1,2}$.
Input circulating current.
Output circulating current.
Balancing ac current for cell capacitor voltages.
DC component of the derivation branch voltage.
AC component of the derivation branch voltage.
Peak value of $i_{i u 1,2}$.
Peak value of $i_{o u 1,2}$.
Peak value of $v_{u}$.
Peak value of $i_{q}$,
Input pole dc voltage.
Output pole dc voltage.
Input dc current.
Output dc current.
Capacitor voltage reference.
Capacitor voltage of the $j t h$ cell of one branch.
Cell capacitance.
Instantaneous branch energy.
$N_{x 1,2}$

\begin{abstract}
$f_{u} \quad$ Frequency of the ac currents and voltages.
$f_{s w} \quad$ Switching frequency.

$V_{x 1,2 c}^{*} \quad$ Voltage reference for each cell obtained from the current control loop.
\end{abstract}

\section{INTRODUCTION}

$\mathbf{H}$ IGH-VOLTAGE dc (HVdc) grids are envisaged to be used to deliver large amounts of renewable power from generation locations, e.g. large off-shore wind farms, to consumptions centers in Europe. In the future, the current pointto-point links will be meshed to create multi-terminal HVdc grids (MT-HVdc) [1], [2].

Voltage Source Converters (VSC) based on Modular Multilevel Converters (MMC) are the preferred technology for the AC-DC and DC-AC conversion [3]-[5]. MMCs offer some advantages such as high quality voltage and current waveforms, low switching frequency, and low power losses.

Multi-terminal HVdc grids with more lines than converter stations require additional equipment for power flow control. Several alternatives have been proposed including highfrequency transformers [6] or even the use of switchable resistors [7]. These configurations have the drawbacks of requiring complex high voltage and high frequency transformers the former and the increase in losses the latter. In [8], the power flow is controlled by inserting a dc voltage in one line of the MT-HVdc. However, it requires an ac grid to create and control the dc voltage. A Current Flow Converter (CFC) also based on the insertion of an dc voltage in the dc lines is proposed in [9].

Because of its advantages, the MMC is also being considered for modular multi-level DC-DC conversion topologies such as those proposed in [10]-[14]. The topology in [10] and [11] is basically a cascade of two standard AC-DC MMC stages which are connected by their ac sides. The first MMC implements the DC-AC conversion stage whereas the second MMC implements the AC-DC conversion stage. A similar alternative but based on the Alternating Arm Converter (AAC) is proposed in [12]. Other topologies with an intermediate ac link are proposed in [13] and [14].

In this paper a Modular Multi-level DC-DC Converter (DC-DC-MMC) is proposed for $\mathrm{HVdc}$ applications. It requires neither the use of a transformer nor an intermediate ac stage. The DC-DC-MMC can be used to either control the power flow in HVdc grids, where the voltage difference between the 


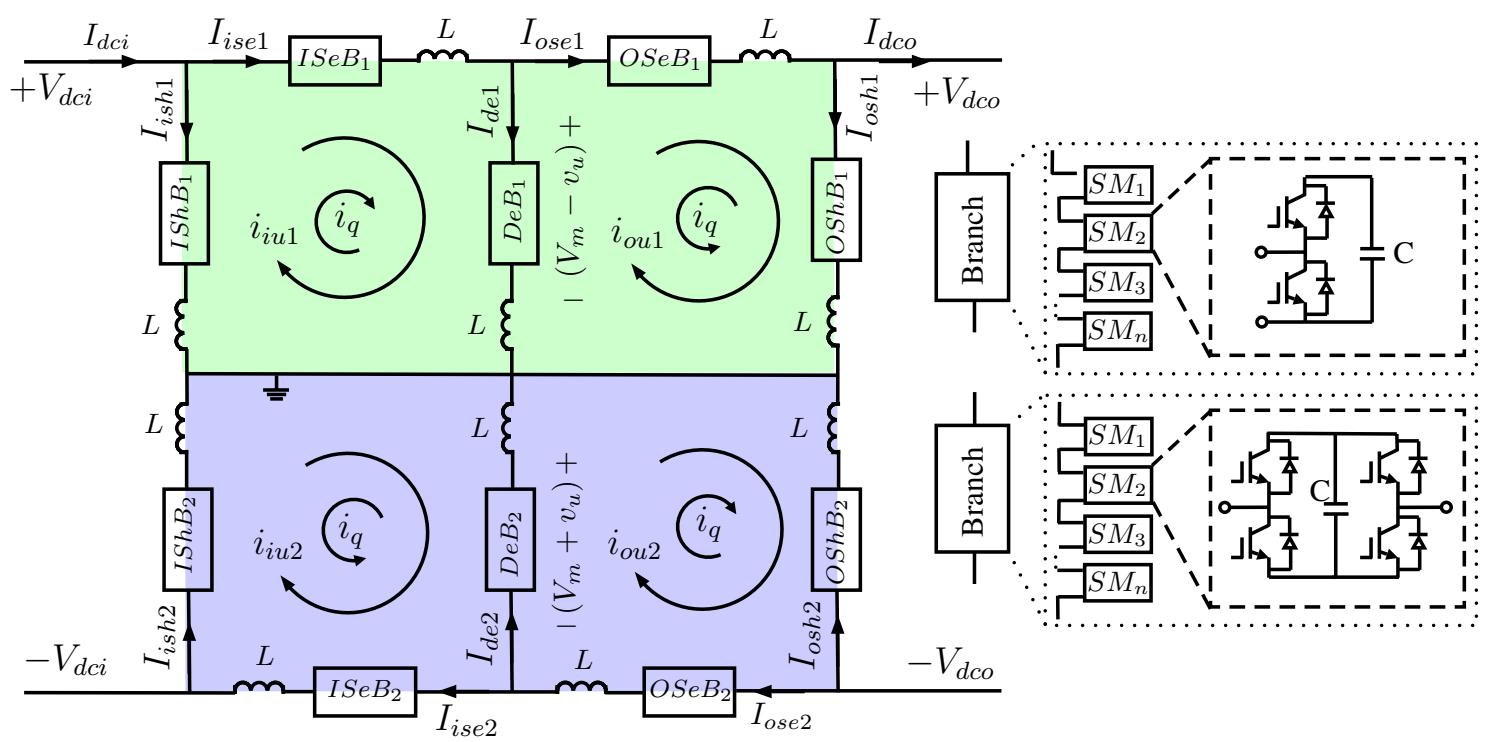

Figure 1: Proposed DC-DC converter topology.

input and the output of the converter is small, or to interconnect $\mathrm{HVdc}$ grids with a significant voltage difference.

\section{Modular Multi-Level DC-DC CONVERTER DESCRIPTION}

The proposed DC-DC-MMC is based on the topology introduced in [15] and [16]. In [15], a MMC converter consisting of three branches arranged in a $\Pi$ topology is used for frequency changing applications. Note that it requires different input and output frequencies for its operation. A similar structure was proposed in [17] for single phase acac conversion but not suitable for high voltage applications as only 2 level converters were considered. Moreover, it also requires different input and output frequencies.

In [16], a MMC consisting of an arrangement of two $\Pi$-MMC is used for DC-DC conversion. The upper $\Pi$ arrangement has a dc voltage $\left(V_{d c i}\right)$ as input and creates a dc voltage plus an ac voltage at the output $\left(V_{m}+v_{u}\right)$. The output ac voltage is necessary as the converter requires different input and output frequencies for its operation. The lower $\Pi$ arrangement works in a similar manner but creates an ac voltage which is shifted $180^{\circ}$ from the voltage of the upper arrangement $\left(V_{m}-v_{u}\right)$. In this way, the total pole-to-pole output voltage is constant and equal to $2 V_{m}$. However the poleto-ground voltages have a ripple due to $v_{u}$.

The proposed topology shown in Fig. 1 consists of the series connection of two double $\Pi$ DC-DC-MMC which work as described in the previous paragraph. The branches of the first double П-MMC converter are named input shunt, input series and input derivation. Analogously, the branches of the second double П-MMC converter are named output shunt, output series and output derivation. The input and output voltages of the first one are:

- Input voltage of the upper part: $V_{d c i}$.

- Input voltage of the lower part: $V_{d c i}$.

- Output voltage of the upper part: $V_{m}+v_{u}$.

- Output voltage of the lower part: $V_{m}-v_{u}$.
The second double $\Pi$ DC-DC-MMC is connected in opposition to the first one, i.e, the two double $\Pi$ DC-DC-MMC are connected by the derivation branches. The input and output voltages of the second one are:

- Input voltage of the upper part: $V_{m}+v_{u}$.

- Input voltage of the lower part: $V_{m}-v_{u}$.

- Output voltage of the upper part: $V_{d c o}$.

- Output voltage of the lower part: $V_{d c o}$.

The derivation branches of both converters are in parallel, so one of them can be removed. In this way, the final proposed topology is shown in Fig. 1, where each branch has $\mathrm{N}$ cells (N can be different for each branch). Depending on $V_{d c i}, V_{d c o}$, $V_{m}$, and $v_{u}$, the series branches may or may not require the insertion of negative voltages. Hence, based on the voltage levels, half- or full-bridge cells will be required for the series branches and half-bridge cells for the the rest of the branches.

The proposed topology can be used for either symmetrical monopolar, bipolar or asymmetrical monopolar configurations of the HVdc grid.

\section{DC-DC-MMC CONTROL}

The strategy for regulating the capacitor voltage of the cells is a two-fold scheme: i) control of the total energy in every branch of the converter and ii) balance the cell capacitor voltages in each branch. Energy can be transferred from one branch to another branch by using circulating ac currents $\left(i_{i u 1,2}\right.$ and $\left.i_{o u 1,2}\right)$ which are in phase with the ac voltage component of the the series and derivation branches $\left(v_{u}\right)$.

The capacitor voltage balance of the $\mathrm{N}$ cells that form a branch is carried out as in [15], [18]. This is done by balancing (N-1) capacitor voltage deviations with respect to the average capacitor voltage of the branch. Each voltage deviation is fed into a dedicated Proportional-Integral (PI) controller which sets the required balancing ac voltage component $\left(v_{q j}\right)$, which is in quadrature to $v_{u}$, for the $j t h$ cell. Additionally, an ac current $\left(i_{q}\right)$, which is in phase with $v_{q j}$ and transfers energy among the 
cells inside a branch, is forced to flow through every branch. This facilitates the control system since it provides decoupling between energy branch balance and capacitor voltage balance. Hence, currents $i_{i u 1,2}$ and $i_{o u 1,2}$ are used to transfer energy among branches and $i_{q}$ is used to transfer energy among the cells in each branch.

\section{A. Branch energy control}

The operating principles of the upper and lower part of the converter are equivalent, hence, only the upper half of the converter is analyzed. The lower half operates in a similar manner but with the derivation branch ac voltage shifted $180^{\circ}$. In the following equations, uppercase variables (voltages/currents) represent $\mathrm{dc}$ components and lowercase variables are ac components.

The input series and derivation branches are controlled in order to obtain a dc voltage plus an ac voltage in each derivation branch. The voltages of the derivation branches are defined as follows:

$$
\begin{aligned}
& v_{m 1}=V_{m}-v_{u} \\
& v_{m 2}=V_{m}+v_{u}
\end{aligned}
$$

where the ac voltage is:

$$
v_{u}=V_{u} \sin \left(2 \pi f_{u} t\right)
$$

Note that the sum of the upper and lower derivation branch voltages $\left(v_{m 1}+v_{m 2}\right)$ is constant. Hence, at this part of the converter there is a constant voltage between the positive and negative pole. However, the pole-to-ground voltages are not constant since they have a ripple due to $v_{u}$.

From Fig. 1, the instantaneous powers in each branch are given by:

$$
\begin{aligned}
& p_{i s h 1}=\frac{d W_{i s h 1}}{d t}=V_{d c i}\left(I_{i s h 1}-i_{i u 1}\right) \\
& p_{i s e 1}=\frac{d W_{i s e 1}}{d t}=\left(V_{d c i}-\left(V_{m}-v_{u}\right)\right)\left(I_{i s e 1}+i_{i u 1}\right) \\
& p_{d e 1}=\frac{d W_{d e 1}}{d t}=\left(V_{m}-v_{u}\right)\left(I_{d e 1}+i_{i u 1}-i_{o u 1}\right) \\
& p_{o s e 1}=\frac{d W_{o s e 1}}{d t}=\left(\left(V_{m}-v_{u}\right)-V_{d c o}\right)\left(I_{o s e 1}+i_{o u 1}\right) \\
& p_{o s h 1}=\frac{d W_{o s h 1}}{d t}=V_{d c o}\left(I_{o s h 1}+i_{o u 1}\right)
\end{aligned}
$$

Taking into account that $v_{u}, i_{i u 1}$ and $i_{o u 1}$ are in phase, the average powers for each branch are $\left(i_{q}\right.$ is not considered in the energy modeling since it is shifted $90^{\circ}$ from $v_{u}$ ):

$$
\begin{aligned}
\frac{d \bar{W}_{i s h 1}}{d t} & =V_{d c i} I_{i s h 1} \\
\frac{d \bar{W}_{i s e 1}}{d t} & =\left(V_{d c i}-V_{m}\right) I_{i s e 1}+\frac{V_{u} I_{i u 1}}{2} \\
\frac{d \bar{W}_{d e 1}}{d t} & =V_{m} I_{d e 1}-\frac{V_{u}\left(I_{i u 1}-I_{o u 1}\right)}{2} \\
\frac{d \bar{W}_{o s e 1}}{d t} & =\left(V_{m}-V_{d c o}\right) I_{o s e 1}-\frac{V_{u} I_{o u 1}}{2} \\
\frac{d \bar{W}_{o s h 1}}{d t} & =V_{d c o} I_{o s h 1}
\end{aligned}
$$

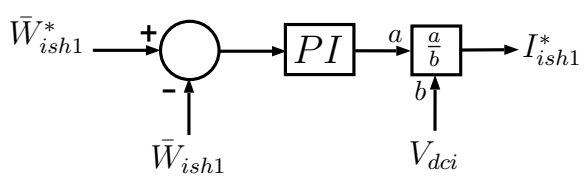

Figure 2: Energy control of the input shunt branch.

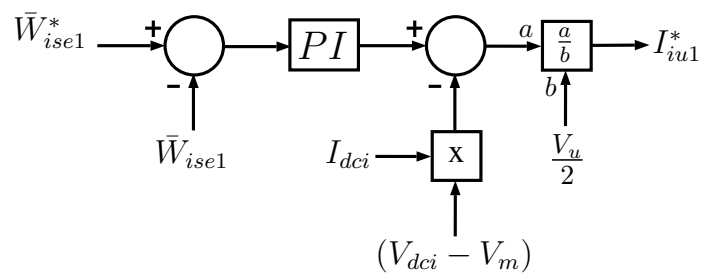

Figure 3: Energy control of the input series branch.

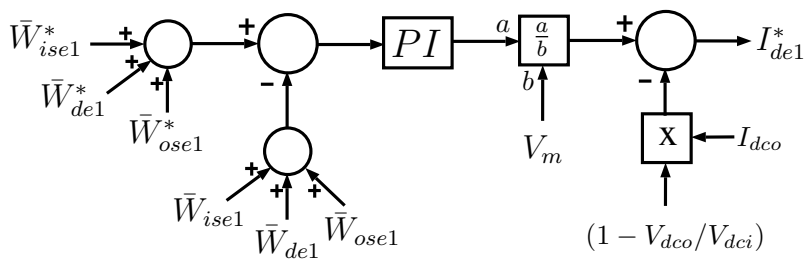

Figure 4: Energy control of the derivation branch.

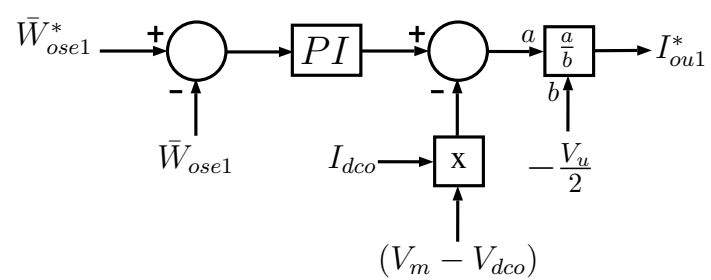

Figure 5: Energy control of the output series branch.

According to (8) and (12), steady state values of $I_{i s h 1}$ and $I_{o s h 1}$ must be zero in order to keep a constant average energy in the shunt branches. Hence, $I_{o s e 1}=I_{d c o}$ and $I_{i s e 1}=I_{d c i}$, so $I_{o s e 1}$ can be considered as a perturbation. Similarly, $I_{i s e 1}$ is determined by the converter voltage ratio and the output current (neglecting losses, $\left.I_{i s e 1}=\left(V_{d c o} / V_{d c i}\right) I_{o s e 1}\right)$. From (9) and (11), it can be noticed that the input and output series branch energies can be controlled by using $i_{i u 1}$ and $i_{o u 1}$, respectively. Adding (9), (10) and (11) yields to:

$$
\frac{d \bar{W}_{i s e 1}}{d t}+\frac{d \bar{W}_{d e 1}}{d t}+\frac{d \bar{W}_{o s e 1}}{d t}=V_{m}\left(\left(1-\frac{V_{d c o}}{V_{d c i}}\right) I_{o s e 1}+I_{d e 1}\right)
$$

Therefore, the total energy in the input series, output series and derivation branches can be controlled by means of $I_{d e 1}$.

The control loops of the branch energies are shown from Fig. 2 to Fig. 6.

\section{B. Branch current control}

The current through each branch consists of a dc component, which is zero for the shunt branches, and an ac component. According to Fig. 1, the currents through each 


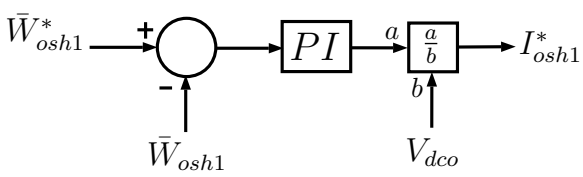

Figure 6: Energy control of the output shunt branch.

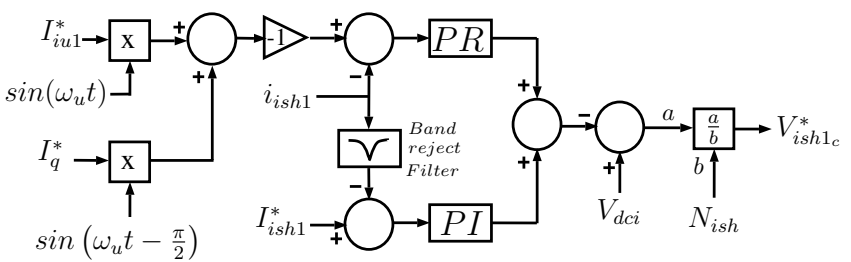

Figure 7: Current control of the input shunt branch.

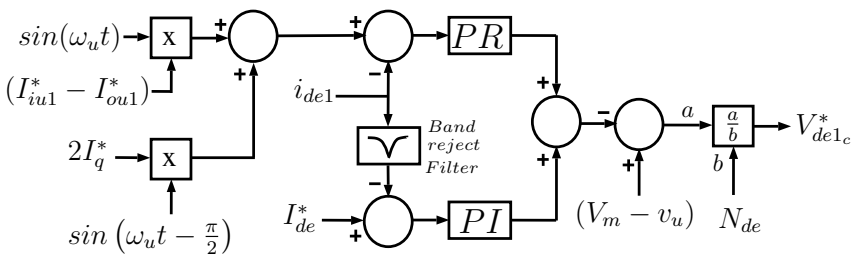

Figure 8: Current control of the derivation branch.

branch are:

$$
\begin{aligned}
i_{i s h 1}= & I_{i s h 1}-I_{i u 1} \sin \left(2 \pi f_{u} t\right)-I_{q} \sin \left(2 \pi f_{u} t-\frac{\pi}{2}\right) \\
i_{i s e 1}= & I_{i s e 1}+I_{i u 1} \sin \left(2 \pi f_{u} t\right)+I_{q} \sin \left(2 \pi f_{u} t-\frac{\pi}{2}\right) \\
i_{d e 1}= & I_{d e 1}+I_{i u 1} \sin \left(2 \pi f_{u} t\right)-I_{o u 1} \sin \left(2 \pi f_{u} t\right) \\
& +2 I_{q} \sin \left(2 \pi f_{u} t-\frac{\pi}{2}\right) \\
i_{o s e 1}= & I_{o s e 1}+I_{o u 1} \sin \left(2 \pi f_{u} t\right)-I_{q} \sin \left(2 \pi f_{u} t-\frac{\pi}{2}\right) \\
i_{o s h 1}= & I_{o s h 1}+I_{o u 1} \sin \left(2 \pi f_{u} t\right)-I_{q} \sin \left(2 \pi f_{u} t-\frac{\pi}{2}\right)
\end{aligned}
$$

Branch currents are controlled by means of a PI controller (for the dc component) and a Proportional-Resonant (PR) controller (for the ac components). The output shunt branch sets the current $i_{o u 1}-i_{q}$. The derivation branch controls $I_{d e}$ and $i_{i u 1}-i_{o u 1}+2 i_{q}$. Finally, the input shunt branch avoids $i_{i u 1}$ and $i_{q}$ to flow though the dc cables by forcing these currents to flow through that branch.

The control loops, whose output is the voltage reference for each cell, are shown from Fig. 7 to Fig. 9. It is not necessary to control the current through the series branches since they are imposed by the derivation and shunt branch currents and the output current. The voltage reference for each cell of the series branches are computed as shown in Fig. 10 and Fig. 11.

\section{Alternative topology}

As it was discussed previously, $I_{i s h 1,2}$ are zero, so the input shunt branches only have to recirculate the ac currents flowing through the rest of the branches. Therefore, the shunt branches can be replaced by a capacitor in order to reduce the losses and the complexity of the converter. In that case, in

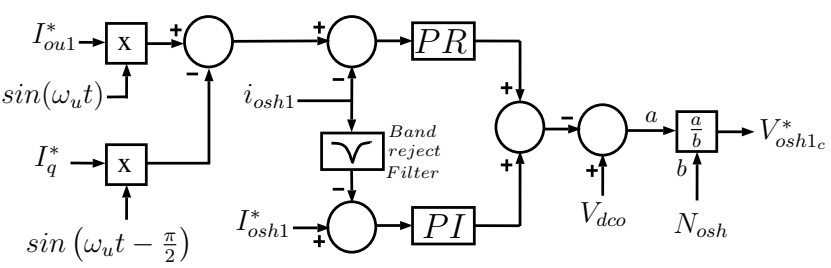

Figure 9: Current control of the output shunt branch.

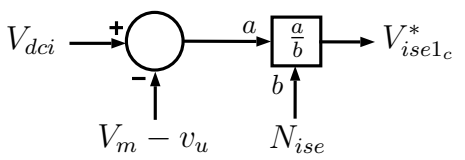

Figure 10: Voltage reference for the input series branch.

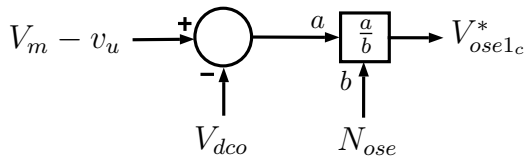

Figure 11: Voltage reference for the output series branch.

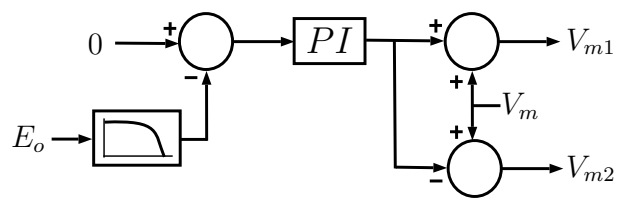

Figure 12: Central branch voltage control.

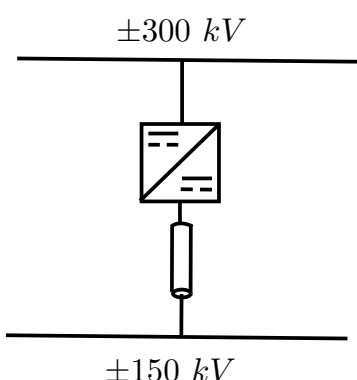

Figure 13: Shematic of the interconnected HVdc grids.

order to allow the ac currents to flow through the capacitors, the central branch of the converter can not be grounded so an additional control loop (see Fig. 12) is necessary to guarantee that the voltage $\left(E_{o}\right)$ of that branch is zero. To do that, a PI controller modifies the dc voltage reference of the upper and lower derivation branches to force the central branch voltage to be zero. Both voltage references are modified by the same value so the pole-to-pole is kept constant (and equal to $2 E_{m}$ ). Note that this control loop is not necessary when cells are used in the shunt branches because the branch can be grounded.

\section{RESUlTS}

The operation of the DC-DC-MMC is validated by means of PSCAD simulations. The system under study is shown in Fig. 13. The DC-DC-MMC converter interconnects two HVdc 
Table I: Converter data.

\begin{tabular}{ll} 
Variable & Value \\
\hline$V_{d c i}$ & $\pm 300 \mathrm{kV}$ \\
$V_{d c o}$ & $\pm 150 \mathrm{kV}$ \\
$C$ & $3000 \mu \mathrm{F}$ \\
$E_{c}$ & $2.5 \mathrm{kV}$ \\
$N_{\text {ise }}, N_{\text {de }}, N_{\text {ose }}, N_{\text {osh }}$ & $100,150,75,75$ \\
$I_{q}$ & $0.1 \mathrm{kA}$ \\
$V_{m}$ & $200 \mathrm{kV}$ \\
$V_{u}$ & $100 \mathrm{kV}$ \\
$L$ & $35 \mathrm{mH}$ \\
$f_{u}$ & $100 \mathrm{~Hz}$ \\
$f_{s w}$ & $500 \mathrm{~Hz}$
\end{tabular}

lines with different voltage levels and the power flow between them is controlled by means of a PI controller that modifies the output voltage of the converter, $V_{d c o}$, in order to control the output current, $I_{d c o}$, to its reference value. The converter topology presented in Section III-C in which the input shunt branches are replaced by capacitors is used. Converter data are presented in Table I. A simplified branch model based on [19] is used to model the converter. For sake of clarity, only the results for the upper half of the converter are presented.

Fig. 14 shows the operation of the system when the power reference is changed. Initially, the power flow between both dc grids is zero. At $t=1 \mathrm{~s}$ the output power reference is ramped up from 0 to $150 \mathrm{MW}$. Then, it is ramped down from $150 \mathrm{MW}$ to $-150 \mathrm{MW}$ at $t=3 \mathrm{~s}$. The power, the positive and negative pole-to-ground voltages and the currents at the input and output converter terminals are shown in Fig. 14. It can be clearly seen that the converter can control the power in both directions, so it is possible to transfer power from the low voltage grid to the high voltage grid.

Fig. 15 shows the current flowing through each branch. It can be noticed that the dc component of the input and output shunt branches are zero as expected from the theory. The input series, output series and derivation branch currents have dc and ac components. Note that the dc components of those currents change their sign due to the power reversal.

The maximum, minimum and average cell voltages in each branch of the converter are shown in Fig. 16. The capacitor voltage balancing control keeps the cell capacitor voltages well-balanced around their reference value. A zoom in the capacitor voltages is shown in Fig. 17.

Fig. 18 shows the upper $\left(v_{m 1}\right)$ and lower derivation $\left(v_{m 2}\right)$ branch voltages and the sum of both of them $\left(v_{m 1}+v_{m 2}\right)$. It can be seen that the total derivation branch voltage is constant. However, the voltage of each branch has an ac component according to (1). Hence, the pole to ground voltage at this point of the converter is not constant.

\section{CONCLUSion}

A novel Modular Multi-level DC-DC Converter (DC-DCMMC) which requires neither the use of high frequency and high voltage transformers nor intermediate ac voltages is presented in this paper. A suitable control strategy is also

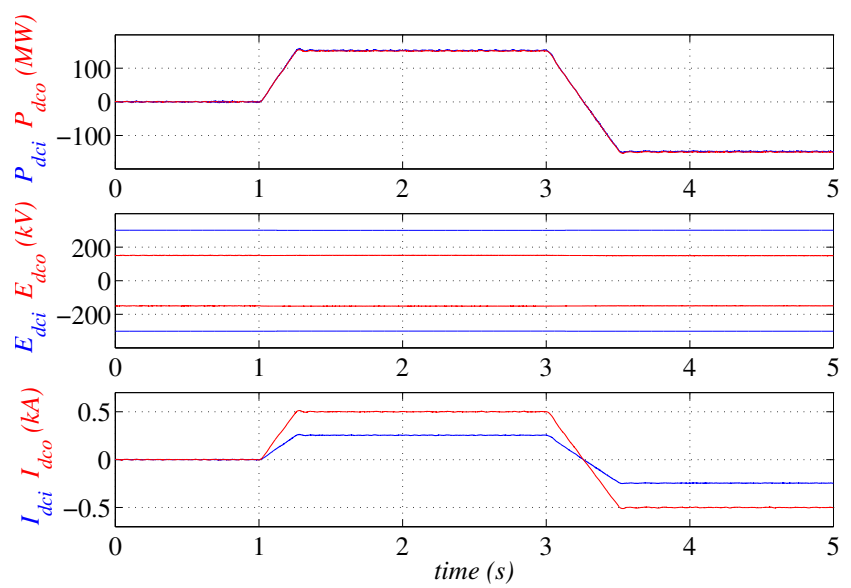

Figure 14: Input and output power, voltage and current.

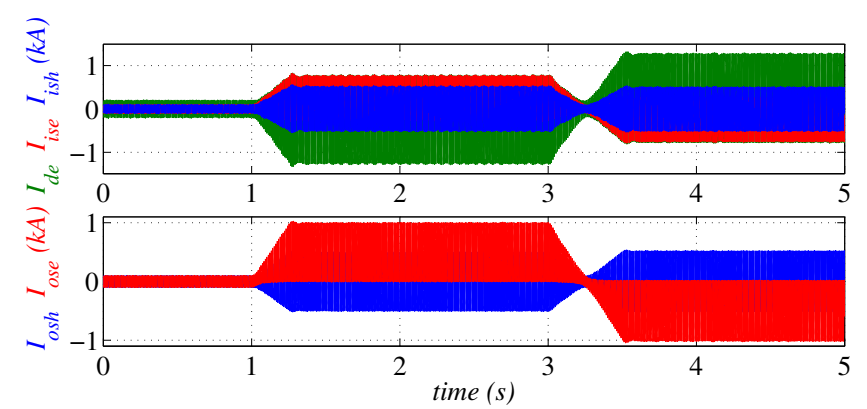

(a)

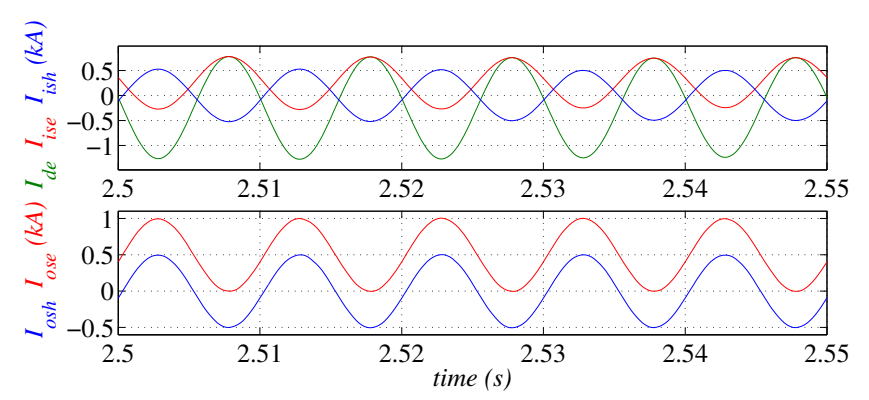

(b)

Figure 15: a) Converter branch currents. b) Zoom in at $t=$ $2.5 \mathrm{~s}$.

proposed for the DC-DC-MMC for both, the branch energy control and the cell capacitor balancing.

The DC-DC-MMC can be used to either control the power flow in HVdc grids, where the voltage difference between the input and the output terminals of the converter is small, or to interconnect $\mathrm{HVdc}$ grids with a significant voltage difference.

The technical viability of the DC-DC-MMC and the control strategy has been thoroughly validated by means of detailed simulations considering a significant number of cells per branch.

\section{ACKNOWLEDGMENT}

The present work was supported by the Spanish Ministry of Economy funds under Grant DPI2014-53245-R and by Universitat Jaume I under Grants P1·1B2013-51 and E-2014-24. The support of Fondecyt Chile under grant 1151325, CONICYT/FONDAP/15110019 is also kindly acknowledged. 

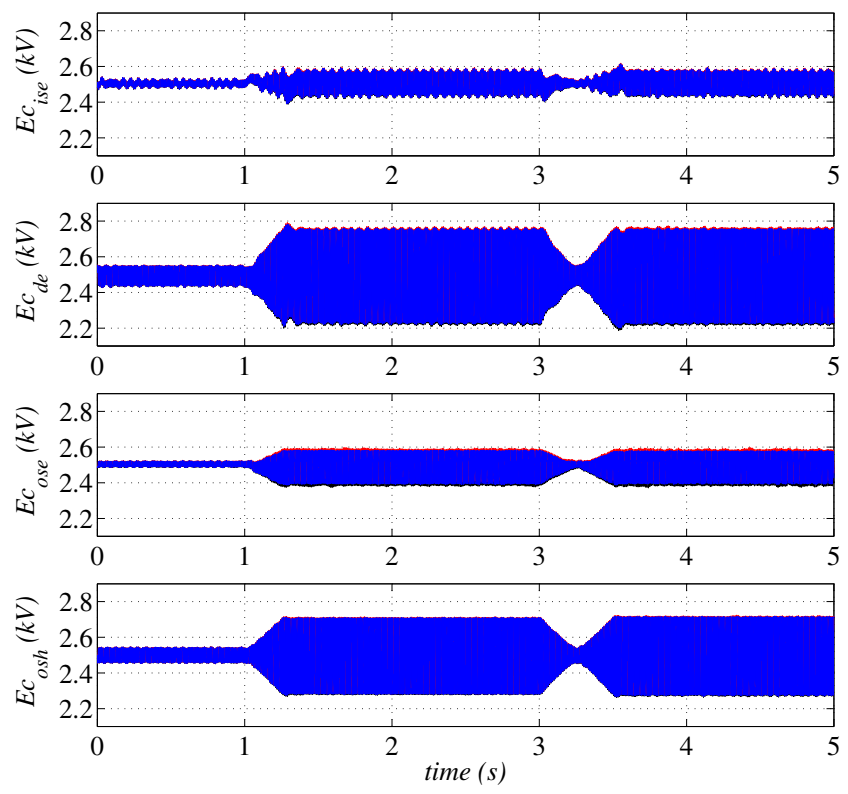

Figure 16: Maximum, minimum and average cell voltages.
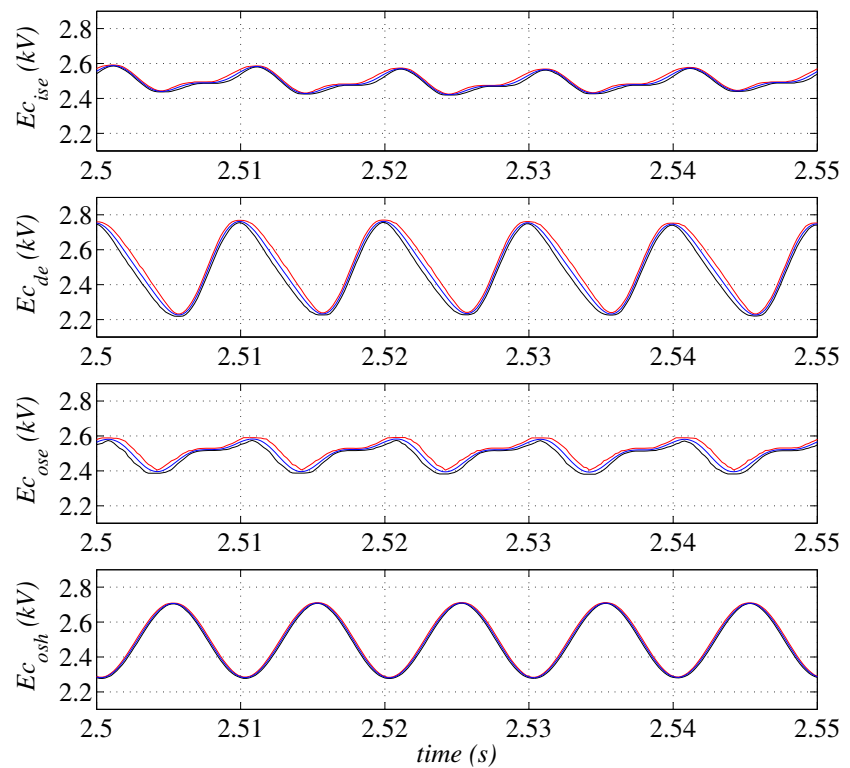

Figure 17: Maximum, minimum and average cell voltages. Zoom in at $t=2.5 \mathrm{~s}$.

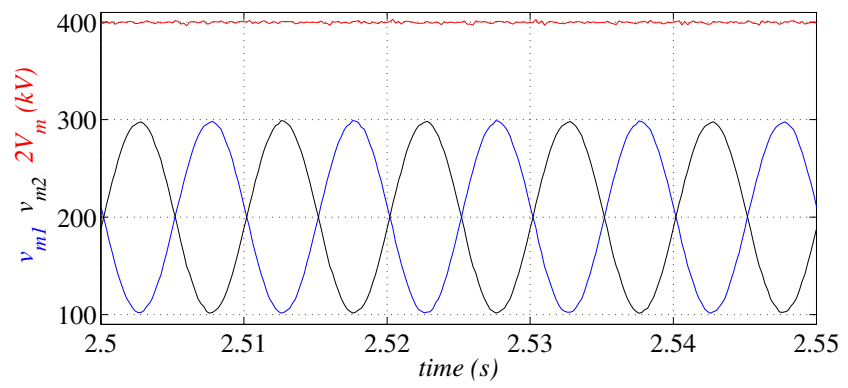

Figure 18: Derivation branch voltages. Zoom in at $t=2.5 \mathrm{~s}$.

\section{REFERENCES}

[1] M. Barnes and A. Beddard, "Voltage Source Converter HVDC Links - The State of the Art and Issues Going Forward," Energy Procedia, vol. 24, pp. 108-122, Jan. 2012.

[2] D. Van Hertem and M. Ghandhari, "Multi-terminal VSC HVDC for the European supergrid: Obstacles," Renewable and sustainable energy reviews, vol. 14, no. 9, pp. 3156-3163, 2010.

[3] A. Lesnicar and R. Marquardt, "An innovative modular multilevel converter topology suitable for a wide power range," in Proc., IEEE Bologna Power Tech. Conf., vol. 3, 2003, pp. 1-6.

[4] J. Dorn, H. Gambach, J. Strauss, T. Westerweller, and J. Alligan, "Trans Bay Cable - A Breakthrough of VSC Multilevel Converters in HVDC Transmission,” in Proc. CIGRE San Franc. Colloq, San Francisco, 2012.

[5] S. Allebrod, R. Hamerski, and R. Marquardt, "New transformerless, scalable Modular Multilevel Converters for HVDC-transmission," in IEEE Power Electron. Spec. Conf., PESC, 2008, pp. 174-179.

[6] S. P. Engel, M. Stieneker, N. Soltau, S. Rabiee, H. Stagge, and R. W. De Doncker, "Comparison of the Modular Multilevel DC Converter and the Dual-Active Bridge Converter for Power Conversion in HVDC and MVDC Grids," IEEE Trans. on Power Electron., vol. 30, no. 1, pp. 124-137, Jan. 2015.

[7] Q. Mu, J. Liang, Y. Li, and X. Zhou, "Power flow control devices in DC grids," in 2012 IEEE Power and Energy Society General Meeting, Jul. 2012, pp. 1-7.

[8] T. Zhang, C. Li, and J. Liang, "A thyristor based series power flow control device for multi-terminal HVDC transmission," in Power Engineering Conference (UPEC), Sep. 2014, pp. 1-5.

[9] C. Barker and R. Whitehouse, "A current flow controller for use in HVDC grids," in 10th IET International Conference on AC and DC Power Transmission (ACDC), Dec. 2012, pp. 1-5.

[10] S. Kenzelmann, A. Rufer, M. Vasiladiotis, D. Dujic, F. Canales, and Y. De Novaes, "A versatile DC-DC converter for energy collection and distribution using the Modular Multilevel Converter," in Proceedings of the 14th European Conference on Power Electronics and Applications (EPE), Aug. 2011, pp. 1-10.

[11] D. Montesinos-Miracle, M. Massot-Campos, J. Bergas-Jane, S. Galceran-Arellano, and A. Rufer, "Design and Control of a Modular Multilevel DC/DC Converter for Regenerative Applications," IEEE Trans. on Power Electron., vol. 28, no. 8, pp. 3970-3979, Aug. 2013.

[12] T. Luth, M. Merlin, T. Green, F. Hassan, and C. Barker, "HighFrequency Operation of a DC/AC/DC System for HVDC Applications," IEEE Trans. on Power Electron., vol. 29, no. 8, pp. 4107-4115, Aug. 2014.

[13] J. A. Ferreira, "The Multilevel Modular DC Converter," IEEE Trans. on Power Electron., vol. 28, no. 10, pp. 4460-4465, Oct. 2013.

[14] S. Norrga, L. Angquist, and A. Antonopoulos, "The polyphase cascaded-cell DC/DC converter," in 2013 IEEE Energy Conversion Congress and Exposition (ECCE), Sep. 2013, pp. 4082-4088.

[15] D. E. Soto-Sanchez, R. Pena, R. Cardenas, J. Clare, and P. Wheeler, "A Cascade Multilevel Frequency Changing Converter for High-Power Applications," IEEE Trans. on Ind. Electron., vol. 60, no. 6, pp. 2118 2130, Jun. 2013.

[16] C. Pesce, R. Peña, D. Soto, J. Riedemann, and R. Blasco-Gimenez, "A multilevel modular DC-DC converter topology," in 11th Int. Conf. on Modeling and Simulation of Electric Machines, Converters and Systems (ELECTRIMACS-2014), 2014, pp. 493-499.

[17] M. Khodabandeh, M. Zolghadri, and N. Noroozi, "A new t-type direct AC/AC converter," in Power Electronics, Drives Systems Technologies Conference (PEDSTC), Feb. 2015, pp. 247-252.

[18] D. Soto, R. Pena, and P. Wheeler, "Decoupled control of capacitor voltages in a PWM cascade StatCom," in IEEE Power Electronics Specialists Conference, PESC, Jun. 2008, pp. 1384-1389.

[19] R. Vidal-Albalate, E. Belenguer, H. Beltran, and R. Blasco-Gimenez, "Simplified model for modular multi-level converter simulation," in 11th Int. Conf. on Modeling and Simulation of Electric Machines, Converters and Systems (ELECTRIMACS-2014), 2014, pp. 487-492. 